\title{
«llustraducción» para niños: las dinámicas texto-imagen en los álbumes infantiles ilustrados desde un prisma traductológico
}

\section{"Illustranslation" for children: Text-illustration dynamics in children's picture books from a translation studies perspective}

\author{
BRUNO ECHAURI GALVÁN 1 \\ bruno.echauri@uah.es \\ Universidad de Alcalá
}

Fecha de recepción: 11 de octubre de 2019

Fecha de aceptación: 20 de marzo de 2020

Resumen: El presente artículo parte de la idea de que traducción e ilustración son procesos que comparten ciertas semejanzas y metodologías. Sobre esta premisa, se pretende demostrar que las dinámicas texto-imagen presentes en los álbumes infantiles ilustrados pueden considerarse el resultado de un proceso traslativo, lo que permitirá sugerir herramientas de análisis para estudiarlas desde esta perspectiva. En este sentido, se proponen las estrategias y procedimientos de traducción como instrumentos útiles para identificar de forma precisa las decisiones del ilustrador $\mathrm{y}$, subsiguientemente, explicar con detalle por qué se crea una dinámica concreta. Las ideas anteriores se ponen en práctica a través del estudio de varios ejemplos que viene a probar cómo este modelo da lugar a un análisis más sólido, sistemático y fundamentado de las relaciones entre texto e ilustración y de los procesos que las conforman.

Palabras clave: Álbum infantil ilustrado, Traducción, Transmutación, Dinámicas texto-ilustración.

Abstract: The present paper builds on the idea that translation and illustration processes share certain similarities and methodologies. Based on this assumption, the article intends to prove that the text-picture dynamics present in children's picture books could be considered the result of a translation process. This assertion paves the way for using translation

${ }^{1}$ Miembro del Grupo de Investigación en Literatura Contemporánea de la Universidad de Alcalá y del grupo de investigación RECEPTION. 
concepts such as "strategies" and "procedures" as analytical tools to underscore illustrators' decisions and, subsequently, explain the reasons behind the formation of a specific dynamic. The aforementioned ideas are tested via the empirical study of several examples. Its results demonstrate that this model helps draw up a more solid, systematical, and well-grounded analysis of text-illustration relationships and the processes that actually shape them.

Keywords: Children's picture books, Translation, Transmutation, Textpicture dynamics.

\section{INTRODUCCIÓN}

Pese a su aparente sencillez, los álbumes infantiles ilustrados son obras que entrañan una asombrosa complejidad tejida, en muchos casos, alrededor de la simbiosis entre dos elementos: el narrativo y el no narrativo. Comprender lo que se dice en este tipo de trabajos es, por tanto, un proceso interactivo que implica necesariamente la combinación de los dos códigos semióticos presentes en la obra (Nodelman, 1988; Lewis, 2001). Sin embargo, la coordinación entre estos códigos no es ni mucho menos singular, sino un fenómeno complicado y sutil (Sipe, 1998) con múltiples aristas. Las dinámicas texto-ilustración se construyen sobre esta premisa para, grosso modo, crear distintos tipos de interrelaciones entre el signo lingüístico y el icónico.

El presente artículo toma como referencia estudios previos del autor (Echauri-Galván, 2019) para profundizar en las relaciones existentes entre estas dinámicas y los estudios de traducción, al tiempo que refuerza la utilidad de conceptos propios de esta disciplina para el análisis de los álbumes infantiles ilustrados. Con este fin, las siguientes páginas pretenden cumplir distintos objetivos. En primer lugar, realizar una revisión sobre algunas de las principales clasificaciones existentes a la hora de catalogar estas relaciones entre texto e imagen. En segundo lugar, subrayar la idoneidad de la traducción como herramienta para estudiar los procesos que dan lugar a dichas dinámicas, destacando cómo estas interseccionan con conceptos como las estrategias y los procedimientos de traducción y demostrando así las analogías existentes entre traducir e ilustrar. Por último, el artículo se centra en ejemplificar el razonamiento anterior a través de un análisis práctico que aúna reflexiones generales y el estudio de una obra concreta: Princess Smartypants (1988/1997) escrita e ilustrada por Babette Cole. Para resaltar la exhaustividad del modelo propuesto, este análisis se contrasta con otros estudios paralelos de la misma obra como el llevado a cabo por Nikolajeva y Scott (2000). 


\section{LAS DINÁMICAS TEXTO-ILUSTRACIÓN Y SUS DISTINTAS CLASIFICACIONES}

Las dinámicas texto-ilustración se apoyan en la figura del lector como un agente activo en la lectura que construye y descodifica ciertos mensajes a partir de un análisis cuidadoso de la interacción entre la narración y su imagen correspondiente (Sánchez Corral, 1995). A lo largo de los años, su naturaleza ha sido explorada por numerosos autores, dando lugar a muy variadas clasificaciones. Una de las primeras fue la categorización dual propuesta por Schwarz (1982), quien distingue entre relaciones de congruencia o de desviación. Para este autor, las primeras abarcan no solo las relaciones armónicas entre ambos elementos, sino también aquellos casos en los que uno de ellos complementa al otro o situaciones en las que texto e imagen se alternan para narrar la historia. En cuanto a las segundas, Schwarz considera como desviación los casos en los que las imágenes se contraponen al elemento verbal o narran una historia alternativa. Estas ideas tuvieron su continuidad en clasificaciones posteriores, algo más exhaustivas y precisas en su uso de la terminología, como la de Cañamares Torrijos (2007) o la de Nikolajeva y Scott $(2000,2001)$.

Para estas últimas, las dinámicas texto-ilustración pueden catalogarse como simétricas, de ampliación, complementarias, de contrapunto o contradictorias. Dentro de estas cinco categorías que, por otro lado, no son absolutas, sino que pueden darse a la vez en algunos casos, la primera hace referencia a las dinámicas en las que el texto y la ilustración reproducen la misma información o, dicho de otro modo, cuentan una misma historia. La ampliación supone que, o bien la ilustración o bien el texto, aportan nuevos (aunque muy limitados) detalles con respecto a la otra parte. Cuando esto se lleva a un nivel más significativo y uno de los dos elementos aporta información verdaderamente relevante y diferente al otro, nos encontramos ante un caso de complementariedad. En las dinámicas de contrapunto, el texto y la imagen se conjugan para transmitir significados que van más allá del ámbito individual. Llevado al extremo, el contrapunto deriva en dinámicas contradictorias en las que el dibujo y el texto se oponen entre sí, estableciendo una ambigüedad que supone todo un desafío para el lector.

Por su parte, Cañamares Torrijos (2007) divide las dinámicas textoilustración en tres categorías principales: cooperantes con el texto, operantes con el texto o, simplemente, no operantes. Las primeras son aquellas que apoyan la comprensión del elemento verbal, ya sea replicando una secuencia concreta o ampliándola con información implícita en el texto. Las segundas son, probablemente, las más complejas y variadas. Las ilustraciones operantes aportan información nueva y obligan al lector a centrarse en ambos componentes para obtener el mensaje completo que el 
discurso intenta transmitir. En este sentido, el abanico de posibilidades es realmente amplio: las imágenes pueden sumar detalles, narrar historias paralelas, anticipar información, describir escenas no narradas o añadir una nueva perspectiva, entre otras. Por último, las ilustraciones no operantes con el texto hacen referencia a aquellas imágenes que, o bien funcionan como elementos independientes, o bien se contraponen al mensaje que transmite el componente textual.

Ambos modelos han sido llevados a la práctica para analizar distintos álbumes ilustrados. Las propias Nikolajeva y Scott (2000) utilizaron su categorización para explorar obras como Sylvester and the Magic Pebble (Steig, 1969) o Princess Smartypants (Cole, 1988/1997), entre otras. En el primer caso, las autoras etiquetan las dinámicas texto-ilustración del álbum como de mínima ampliación, describiendo el texto como un elemento mucho más rico que las imágenes. Estas, pese a reflejar fielmente y con numerosos matices las expresiones y sentimientos de los personajes, "do not add much that is different» (p. 230) a lo que exponen las palabras, que son las que llevan el peso fundamental de la historia. Por el contrario, el segundo libro, de marcado tono humorístico, se construye sobre dinámicas de contrapunto que crean situaciones irónicas. Así, Nikolajeva y Scott determinan que la imagen, en muchas ocasiones, amplía lo dicho en el «sometimes bland verbal text» (p.232), aportando elementos nuevos e inesperados que se tornan imprescindibles para comprender el verdadero significado de la narración y captar el humor que la autora/ilustradora pretende crear.

Cañamares Torrijos (2007) también comenta varios ejemplos aplicando su modelo. Así, nos describe cómo en obras como Contando ositos de goma (Boegehold, 1997/1999) o Míster Magnolia (Blake, 1980/1995) «las ilustraciones reiteran lo que el texto cuenta» (p.305), idea que encaja en su concepto de ilustración cooperante. Pasando a la categoría de imágenes operantes con el texto, la autora analiza múltiples casos dependiendo de la función que desempeñan las ilustraciones. Por trazar un paralelismo con el párrafo anterior, nos detendremos en distintos ejemplos de imágenes que aportan información nueva a lo expresado en el texto. Dichos ejemplos pueden encontrarse, entre otras, en obras como De cómo nacieron las sirenas (Castro, 2000). En un momento de la narración, el texto indica que la protagonista por fin encontró una salida, mientras «en la ilustración comprobamos que la niña consigue escapar por el espiráculo de la ballena» (Cañamares Torrijos, 2007, p.323). Unas páginas más adelante, se subraya cómo, en ocasiones, las imágenes del libro sirven para anticipar información. Es el caso del pasaje en el que «la imagen que acompaña al texto: "estuvo nadando y nadando hasta que su cabeza dio 
contra algo", muestra contra qué ha chocado: un barco» (Cañamares Torrijos, 2007, p.324). Según la autora, esta inclusión avanza de algún modo la lectura, ya que nos adelanta un detalle de la trama que el discurrir de la narración permitirá corroborar (o desmentir).

Pese al indudable interés y valor de los análisis anteriores, en todos los casos descritos hay un paso que apenas se concreta: las decisiones que conducen al resultado. En otras palabras, las autoras, más allá de señalar si el texto es más o menos rico que la imagen, describir que aparecen elementos nuevos o relatar si se replica de manera precisa el contenido del elemento narrativo, no exploran ni categorizan de manera sistemática los distintos procesos que pueden llevar a una u otra realización. Estos vacíos son algo que los estudios de traducción pueden cubrir si se aplican al análisis de las dinámicas texto-imagen. Así, un ilustrador no decide obviar una parte de la información recogida en el texto, sino que emplea la omisión como recurso. Tampoco "reitera lo que el texto cuenta», sino que lleva a cabo una traducción literal. Del mismo modo, ya no se «añaden» o «dibujan» elementos adicionales, sino que el razonamiento se torna, necesariamente, más profundo y complejo. ¿Es información que pueda inferirse del texto? Nos encontramos, pues, ante un procedimiento de explicitación. ¿Se trata de nuevos detalles? Deberemos entonces pararnos a analizar si el ilustrador ha optado por la amplificación como herramienta o por otro procedimiento de expansión diferente.

En consecuencia, al margen de etiquetar esas decisiones intermedias que dan forma a la ilustración final, el uso de los procedimientos y estrategias de traducción en este contexto aporta una mayor riqueza al análisis, ya que permiten introducir matices entre fenómenos similares (que no iguales) y explicar de forma más clara por qué se acaba produciendo una dinámica u otra entre ambos elementos. Aplicar un modelo así presupone la similitud entre los procesos de traducción e ilustración que se sustenta en el apartado siguiente

\section{2. ¿ILUSTRAR ES TRADUCIR?}

Para trazar el primer nexo entre traducción e ilustración conviene remitirse al concepto de «traducción intersemiótica» o «transmutación» acuñado por Jakobson (1959/2000). En palabras de este autor, dicho concepto engloba los procesos traslativos que se dan entre dos sistemas de signos diferentes. Así, la transmutación abarca una fenomenología muy variada, desde la adaptación de una novela al cine, hasta el dibujo que surge de una canción, pasando por un poema interpretado a través de una melodía. 
Sobre esta teoría seminal ha germinado un acalorado debate orientado a dirimir si la transmutación debe/puede considerarse o no traducción. En este sentido, el paso de los años ha visto cómo se consolidaban posturas muy diferentes al respecto. Puesto que entre los propósitos de este artículo no se cuenta dar solución a esta controversia, las siguientes líneas tratan simplemente de describir dos propuestas distantes en su planteamiento que contextualicen la discusión y permitan, al mismo tiempo, justificar el enfoque que se va a seguir en secciones posteriores.

Por un lado, autores como Eco (2003/2008) aplican las ideas de Peirce al campo de la traducción para considerar los procesos que conciernen a esta disciplina como fenómenos dentro de un concepto más amplio como el de «interpretación». Esta conceptualización implica asumir la imposibilidad de encontrar una equivalencia total, ya que presupone la construcción de un texto meta (TM) en base a distintos factores como pueden ser la interpretación del propio traductor, el código de destino y los distintos significados que la fuente adquiere en este código o el propósito de la versión final, entre otros. Del mismo modo, la interpretación abarcaría fenómenos tan dispares como la sinonimia, la traducción interlingüística, las refundiciones $\mathrm{y}$, también, las interpretaciones intersemióticas (Eco, 2003/2008).

Pese a mostrarse de acuerdo en considerar la equivalencia total como una entelequia, Calabrese (2000) propone restringir el alcance del término «interpretación» para, de algún modo, desgajar la traducción de otros procesos semióticos y concederle su propio espacio. Así, Calabrese establece que aquellos fenómenos en los que la fuente original pueda reconocerse en la obra resultante, por mucho que esta construya su propio significado(s), deberían entenderse como «traducción». En consecuencia, cree más conveniente hablar de distintos niveles de (im)perfección que analizar la traducción como un punto más dentro de esa inmensa constelación que compone la semiótica. Estos planteamientos son llevados al campo de la transmutación a través de la aplicación de conceptos como el de «traducción molecular» (pegada al texto original, muy similar a la traducción palabra por palabra) o «traducción molar» (más libre y que trata el texto como un sistema) al estudio de distintas operaciones traslativas, incluidas aquellas en las que se produce cambio de materia.

En definitiva, siguiendo las pautas marcadas por Calabrese y al margen de disquisiciones terminológicas, los lazos de la obra original con su versión meta nos pueden permitir analizar ciertos procesos que se alejan de la traducción "propiamente dicha» (esto es, interlingüística) como casos de traducción al fin y al cabo. Dentro de estos procesos, podrían encuadrarse las transmutaciones de texto a ilustración. En línea con lo expuesto en el 
párrafo anterior, no puede obviarse que, en estos supuestos, la composición de la obra final incluirá la creatividad, estilo y libertad del «mediador» a la hora de representar los elementos narrativos del original de una forma determinada. Sin embargo, al mismo tiempo, el resultado mantendrá una interrelación con su fuente, replicando sus rasgos en mayor o menor medida y conservando así cierta fidelidad para con ella.

Estos postulados permiten situar la traducción y la ilustración en planos similares y establecer paralelismos entre ambas disciplinas. En este sentido, voces como las de Pereira (2008) o Martinovski (2016) han defendido que la ilustración se lleva a cabo de una forma muy similar a la traducción y que ambas comparten una serie de metodologías comunes. En otras palabras, traductores e ilustradores toman a menudo decisiones análogas a la hora de llevar a cabo su labor. Estas decisiones tienen mucho que ver con lo que Eco (2003/2008) definió como «negociación», esto es, el proceso mediante el cual el traductor decide qué elementos del TO quiere conservar, destacar, opacar...en su TM. Dicha negociación está a su vez presente a la hora de ilustrar un libro; como sostiene Pereira (2008), esta labor también implica renuncias y la elección de ciertos aspectos o pasajes que reflejar, soslayar o modificar.

Los argumentos previos vienen a sustentar el uso de los estudios de traducción como instrumento para explorar al menos parte de las decisiones del ilustrador. De este modo, herramientas tradicionalmente asociadas a la traductología como los procedimientos y estrategias de traducción pueden resultar útiles para analizar las transmutaciones de texto a imagen que se dan en los álbumes infantiles ilustrados.

\section{DINÁMICAS TEXTO-ILUSTRACIÓN: EL RESULTADO DE «TRADUCIR»}

Si ilustrar es, en parte, traducir, las dinámicas texto-ilustración pueden entenderse como el resultado de un proceso traslativo. Tal y como se comentaba en apartados anteriores, estas dinámicas dependen de la información que el elemento visual replica, omite o modifica con respecto al texto. Esto no es sino una analogía con las tan variadas relaciones que pueden establecerse entre un TO y su TM en la traducción interlingüística. Igual que una dinámica simétrica replica su fuente original, una traducción literal se mantiene fiel a su texto de origen. Del mismo modo, una dinámica complementaria o de ampliación nos aporta más detalles de los que el texto quiere mostrar, algo que también ocurre con traducciones interlingüísticas más explicativas que su TO. Y, al igual que una ilustración puede romper con su fuente para mostrarnos otros puntos de vista o crear efectos nuevos, un texto puede ser reescrito o ajustado (de muy distintas formas) para

Hikma 19 (1) (2020), 187 - 208 
destapar significados alternativos que el original no explotaba y que se consiguen a partir del tamiz de la traducción.

Ante los nexos observables entre ejemplos tan variados, resulta lógico pensar que el proceso de construcción de una imagen o de un texto meta tenga puntos en común. Como se señalaba en el apartado previo, traducción e ilustración se basan en decisiones, muchas veces, similares. Históricamente, los procedimientos de traducción han sido una de las herramientas más empleadas a la hora de catalogar las decisiones tomadas por los traductores. Autores como Pereira $(2007,2008)$ ya utilizaron estos instrumentos para el análisis de las ilustraciones de distintas obras, incluso abordando tangencialmente el efecto de estas decisiones en el diálogo que se crea entre texto e imagen. Sin embargo, sus investigaciones no ahondan en la intersección entre la traducción y las dinámicas texto-imagen, algo hacia lo que sí se orienta el presente trabajo.

Según Delisle, Lee-Jahnke y Cormier (1999), los procedimientos de traducción son aquellos métodos usados por los traductores para tratar de buscar un equivalente en la lengua meta para los elementos significativos que contiene el TO. A lo largo de los años, múltiples autores han tratado de catalogar estos procedimientos ${ }^{2}$ a través de distintas clasificaciones. Una de las más reconocidas ( $\mathrm{y}$ reconocibles) es la propuesta por Vinay y Darbelnet (1958/1995), que contemplaba, fundamentalmente, siete procedimientos: préstamo, calco, traducción literal, transposición, modulación, equivalencia y adaptación. A esta se sucedieron muchas otras, más abarcadoras y/o centradas en fenómenos diferentes, como la de Nida (1964), Vázquez Ayora (1977), Malone (1988) o Hurtado Albir (2001).

Si trabajamos sobre la asunción de los paralelismos existentes entre traducir e ilustrar, podemos comprobar cómo muchos de los procedimientos propuestos por estos y otros académicos pueden aplicarse en el proceso de ilustración y, posteriormente, identificarse en la conformación de distintas dinámicas texto-imagen. Así, una traducción literal que replique palabra por palabra y de forma precisa el significado del TO puede llevarse al terreno de la ilustración dibujando elementos iguales a los que describe el texto. Del mismo modo, las omisiones (o «elisiones» si empleamos la terminología propuesta por Hurtado Albir, 2001) identificables en una obra traducida encuentran su réplica en el dibujo que decide obviar ciertos detalles del texto original (TO). Incluso otros procedimientos menos habituales o más complejos pueden también observarse en el plano ilustrativo. Por ejemplo,

${ }^{2}$ Pese a mantener el mismo significado, el concepto de «procedimiento» recibe distintas denominaciones dependiendo del autor. Así, ha sido catalogado como «método», «estrategia» o «técnica», entre otros. 
la adaptación, basada en adecuar el contenido a la visión propia de cada lengua (Vázquez Ayora, 1977), puede ser implementada a través de una ilustración orientada a las particularidades de un público meta o tiempo de recepción concretos. Y es que, como señala Pereira (2008), los ilustradores han tenido históricamente la capacidad de adaptar sus trabajos a una audiencia, ideología, tiempo o valores concretos, aportando y transmitiendo así nuevos significados a la obra original.

Pese a la confusión terminológica y los solapamientos que en ocasiones genera el largo listado de clasificaciones de procedimientos de traducción disponibles, su exhaustividad y la posibilidad de poder combinarlas permiten englobar la mayor parte de fenómenos observables en las transmutaciones de texto a ilustración. A fin de cuentas, todo consiste en analizar concienzudamente la relación entre elemento narrativo y no narrativo en busca del procedimiento adecuado.

En un segundo estadio, a partir de la apropiada identificación de los procedimientos de traducción aplicados, podremos determinar la estrategia seguida por el ilustrador en un primer momento. Este concepto, acuñado por Vinay y Darbelnet (1958/1995) y recogido posteriormente por otros autores como Vázquez Ayora (1977), sirve para definir la aproximación general del traductor al texto, algo que puede extrapolarse también al ámbito del presente estudio. Según los autores antes citados, dicha aproximación se evalúa en términos de literalidad o libertad, dando lugar a la dualidad entre traducción directa y oblicua. Así, la primera define aquel enfoque que busca adherirse al original, mientras que la segunda hace referencia a las estrategias que se alejan del texto fuente.

A pesar de que en la teoría la distinción parezca muy categórica, la práctica pone de manifiesto lo líquido de la frontera entre estos dos conceptos y constata que la pureza en su aplicación no deja de ser, en muchas ocasiones, un desiderátum. Esta afirmación, llevada a nuestro contexto de estudio, implica que en un mismo trabajo pueden coexistir procedimientos propios de estrategias directas y oblicuas que resulten en el intercalado de, por ejemplo, dinámicas simétricas, de ampliación, de oposición...En un análisis macro que englobe todas las ilustraciones de un álbum o libro ilustrado, la discusión sobre estrategias puede permitir determinar si el ilustrador ha tenido como prioridad mantenerse fiel al escrito, si, por el contrario, ha decidido alejarse de él sistemática o habitualmente o si no existe una estrategia clara a la hora de abordar la ilustración de la obra. A partir de aquí, pueden realizarse numerosas inferencias relacionadas, entre otros aspectos, con los objetivos o público meta de la publicación o con el grado de exigencia al que busca someterse al lector. 


\section{Metodología}

El siguiente análisis pretende ejemplificar las ideas desarrolladas hasta ahora a través del estudio de casos concretos. Para ello se han escogido, en primer lugar, dos imágenes de una de las obras comentadas por Nikolajeva y Scott en su artículo del año 2000, Princess Smartypants (Cole, 1988/1997). Con esto se busca demostrar cómo un mismo ejemplo puede también abordarse desde un prisma traductológico, lo cual, como veremos, aporta especificidad, solidez y una cadena de causalidad al análisis. Asimismo, y como botón de muestra de la aplicabilidad de las ideas de este trabajo a muy variados contextos, se reflexionará brevemente sobre otros supuestos en los que intervienen dinámicas texto-imagen más sencillas que las de la obra de Cole.

Como herramientas traductológicas se emplearán tanto las estrategias como los procedimientos de traducción descritos en apartados previos. En relación con los últimos y en base a la fenomenología que presentan los ejemplos de transmutación comentados, se ha decidido emplear el siguiente listado, obtenido de Hurtado Albir (2001) y adaptado al campo de las transmutaciones texto-ilustración:

- Amplificación. Supone añadir elementos no formulados en el texto fuente. En el ámbito de la transmutación, pueden considerarse como amplificaciones aquellos detalles de la imagen que aportan información completamente nueva en relación con el texto.

- Elisión. Implica la eliminación de elementos presentes en el texto original. En nuestro marco de trabajo, este procedimiento puede identificarse en los aspectos textuales omitidos en las ilustraciones.

- Variación. Modificación de elementos lingüísticos o paralingüísticos que afectan a distintos aspectos del TM como el registro, el estilo o el tono. En transmutaciones como las que aborda este artículo, las variaciones se producen cuando el ilustrador modifica aspectos concretos recogidos en el texto que ocasionan cambios de tono o estilo en la imagen.

- Traducción literal. Cuando entre TO y TM se produce una equivalencia palabra por palabra. En nuestro caso, implica replicar en la ilustración, con la mayor precisión que el cambio de medio permita, segmentos de información contenidos en el texto. 
A estos procedimientos se añade otro tomado de la clasificación propuesta por Vázquez Ayora (1977): la explicitación. Este fenómeno, que implica explicitar en el TM lo que está implícito en el TO, puede aplicarse también a nuestro marco de trabajo en aquellos casos en los que la ilustración incluye información que el texto no refleja literalmente, pero que resulta fácilmente deducible. Como se mencionaba anteriormente, la variedad de procedimientos de traducción disponibles permite modificar las herramientas de análisis, ampliando o reduciendo su número en función de nuestras necesidades y de las fuentes primarias sobre las que estemos trabajando.

De cara al estudio de las dinámicas de Princess Smartypants, se analizarán por separado tres escenas del álbum que incluyen el texto y su ilustración correspondiente. En una primera fase, se determinarán los procedimientos empleados por la autora/ilustradora a la hora de transformar las palabras en imágenes. Esta identificación permitirá subrayar de forma precisa la información que se ha añadido, modificado u omitido con relación al elemento narrativo, lo que posibilitará establecer con claridad las dinámicas texto-ilustración que se den en cada caso. Los resultados obtenidos en estos estadios se emplearán finalmente para tratar de concretar la estrategia de traducción aplicada por Cole a lo largo de las páginas del álbum.

El comentario posterior, referente a obras en las que predominan dinámicas más sencillas, se orienta a probar la replicabilidad del modelo en contextos distintos al estudiado en mayor profundidad. Se espera que el conjunto de este análisis ayude a constatar la estrecha relación entre traducción e ilustración y, por consiguiente, subrayar la utilidad de varios conceptos traductológicos como herramientas para el estudio de las dinámicas texto-imagen y sus implicaciones en los lectores.

\section{ANÁLISIS}

En apartados previos, mencionábamos el álbum Princess Smartypants (Cole, 1988/1997) y el análisis de sus ilustraciones llevado a cabo por Nikolajeva y Scott (2000). Esta historia, en la que el humor juega un papel fundamental, nos presenta a una princesa rebelde que se niega a casarse y que, para evitar el temido camino al altar, se dedica a someter a todos sus pretendientes a pruebas imposibles. En lo que respecta al componente textual, a lo largo del álbum prevalecen las descripciones breves y sencillas, entre las que, en contadas ocasiones, se intercalan segmentos de texto algo más extensos y complejos. El vocabulario empleado es fácilmente entendible por un público infantil y solo algunos 
términos concretos (phrasal verbs o el nombre de algún pretendiente de la princesa) podrían considerarse ligeramente más complicados.

Las ilustraciones, sin embargo, presentan una gran riqueza visual y generan numerosos aspectos de análisis. Tras un estudio general de su interrelación con el texto, Nikolajeva y Scott (2000) concluían que la adición de nuevos e inesperados detalles en la mayor parte de las ilustraciones derivaba en un predominio de las dinámicas de contrapunto con efecto irónico, algo que obliga al lector a analizar tanto el elemento narrativo como el no narrativo para saber qué está pasando verdaderamente en las páginas de la obra de Cole.

Aceptando el diagnóstico en lo que a las dinámicas resultantes respecta, aplicar un prisma traductológico puede permitir un análisis más complejo y detallado que exponga el encaje de las distintas decisiones que acaban conformando una dinámica concreta. En este sentido, como se viene defendiendo a lo largo de este trabajo, las conexiones entre ilustradores y traductores permiten emplear ciertas herramientas de estos últimos para estudiar de manera más concreta lo ocurrido al volcar el contenido del texto en una imagen.

Centrémonos, por ejemplo, en la siguiente escena del álbum: She sent prince Bashthumb to chop some firewood in the royal forest (véase imagen $1^{3}$ ). En este caso, una reproducción fiel del elemento narrativo debería dar lugar a una escena en la que el príncipe Bashthumb apareciese cortando leña en un bosque. Sin embargo, siguiendo el tono humorístico que impregna casi cada página del álbum, la imagen es muy distinta y nos muestra al príncipe huyendo despavorido ante el ataque de los malévolos árboles que pueblan el bosque. Vemos, por tanto, como la ilustradora ha «modificado», «añadido» $e$ incluso «eliminado» ciertos detalles. Pero profundicemos en estos fenómenos.

\footnotetext{
${ }^{3}$ Puesto que la obra de Cole no incluye números de página, se ha decidido incluir una paginación propia para facilitar la identificación de las referencias.
}

Hikma 19 (1) (2020), 187 - 208 


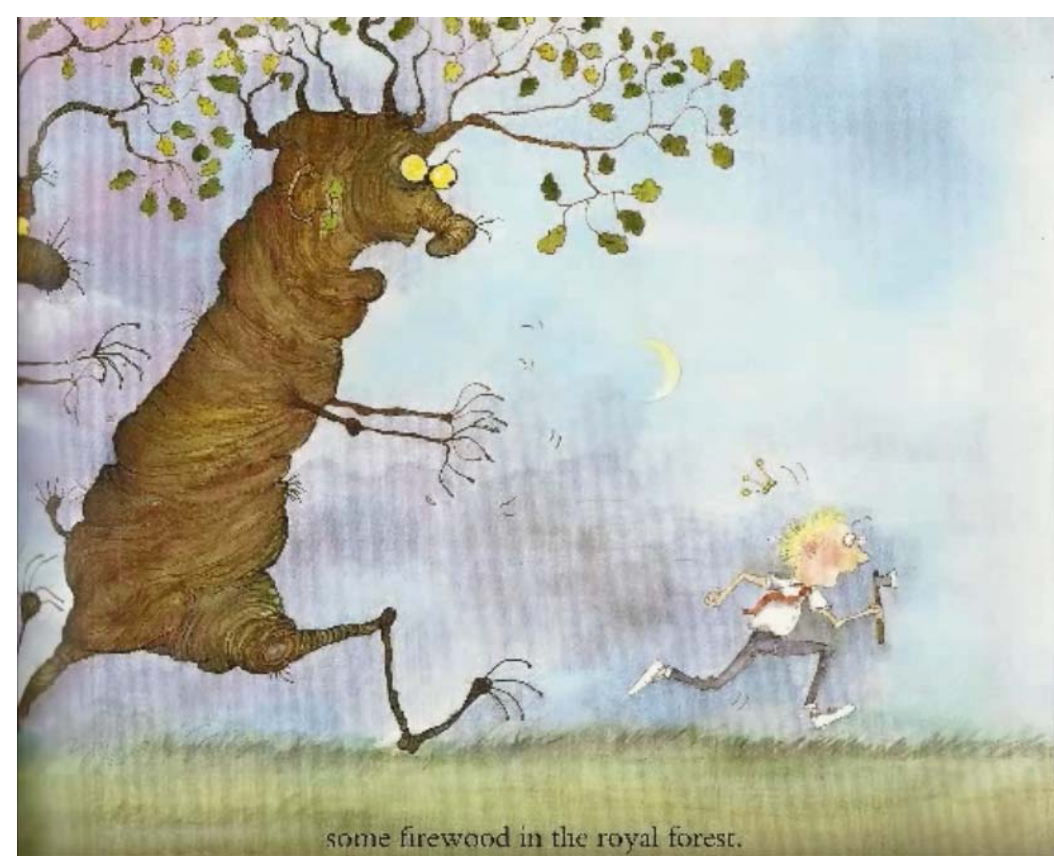

Imagen 1. Princess Smartypants

Fuente: Cole (1988/1997, p.14)

En lo concerniente a los cambios introducidos, nos encontramos fundamentalmente con un procedimiento de variación, puesto que la ilustradora ha modificado en la imagen ciertos rasgos del texto para conseguir un giro en el tono que derive en un efecto humorístico. Este procedimiento se aplica sobre dos ítems concretos: los árboles y el comportamiento del príncipe. Los primeros no son árboles al uso, sino elementos que cobran vida, convirtiéndose en figuras amenazantes que persiguen al príncipe Bashthumb. Este, a su vez, no aparece cortando leña como cabría esperar, sino que huye aterrorizado ante el ataque de los malvados árboles.

Por otro lado, Cole decide añadir una serie de detalles que el elemento narrativo no presenta. A este respecto, debemos diferenciar entre dos procedimientos distintos: explicitación y amplificación. El primero no disrumpe la conexión entre el la imagen y el texto, sino que se limita a hacer visible información implícita en este último. En esta escena, la explicitación puede observarse en la representación de elementos como la hierba o en el hecho de que los personajes se encuentren en un espacio abierto. Puesto 
que la acción discurre en un bosque, es normal que estos detalles estén presentes en el dibujo. Lo mismo sucede con el hacha que el príncipe porta en la mano, objeto que no debería sorprender al lector, ya que la prueba a la que la princesa quería someterle implicaba talar madera.

Otros detalles, sin embargo, aportan información nueva que no está presente de ningún modo en el elemento narrativo y que el lector no puede inferir de él, siendo, por tanto, amplificaciones introducidas por la ilustradora. Un ejemplo sería la luna que contempla la persecución desde el fondo de la imagen. Este elemento nos indica el momento del día en el que transcurre la acción, algo a lo que en ningún momento se hace referencia en el texto. También podrían entrar dentro de esta categoría aspectos como la apariencia del príncipe, la cual no aparece descrita en ningún punto del elemento verbal. Por contra, conviene subrayar que la elisión se ha aplicado a la figura de la princesa, mencionada en el texto dando una orden al príncipe, pero no incluida en la imagen.

Algo similar a lo descrito en este primer ejemplo ocurre en otros puntos del texto, como en las páginas 7 y 8 (véase imagen 2). En este caso, el elemento narrativo nos indica que la princesa ha pedido al príncipe Compost que se encargue de las babosas que amenazan su jardín (She asked prince Compost to stop the slugs eating her garden). La imagen que por individual crearía este elemento es la de una persona recogiendo pequeñas babosas de un jardín o eliminándolas con algún producto a tal efecto. Sin embargo, Cole vuelve a introducir un contrapunto irónico a través de la ilustración, convirtiendo a las babosas en seres descomunales y peligrosos que hacen que el pobre Compost abandone la escena a toda velocidad.

La pauta seguida por la autora a la hora de elaborar esta imagen guarda obvios paralelismos con la del ejemplo anterior. La variación, en este caso, vuelve a afectar a las acciones del príncipe y se extiende también a las babosas del jardín. Estas no son pequeños seres blandos y oscuros que se arrastran por el suelo, sino una especie de gusanos gigantescos con patas, colmillos y claros instintos asesinos. Por su parte, el príncipe Compost (cuyo nombre, al igual que el de todos los príncipes del cuento, no carece de ironía) no se dedica a acabar con la supuesta plaga de babosas, sino más bien a evitar que esta acabe con él, huyendo del lugar tan rápido como le permiten sus piernas y lanzando al aire todos los aparatos de jardinería que había traído consigo. En ambos casos, Cole modifica el significado del elemento narrativo a través de la ilustración para conseguir crear un efecto humorístico basado en la contraposición entre ambas partes. 
En este segundo ejemplo de análisis la explicitación también juega un papel importante. Así, la autora decide incluir varios elementos que el texto no menciona directamente, pero que pueden deducirse de forma lógica a partir de él. Dentro de este fenómeno encontramos las flores, las piedras y los tiestos de la ilustración, todos ellos parte integrante de casi cualquier jardín en el que podamos pensar y necesarios para «dibujar» el contexto en el que transcurre la escena. En esta categoría también podrían incluirse las ropas del príncipe, acordes con lo que el lector puede esperar de un personaje de semejante estatus, y los distintos aparatos de jardinería que porta para combatir a las orugas (la paleta, la horca y lo que parece ser un bote con algún tipo de veneno). De este modo, la autora explicita los medios con los que el príncipe pensaba frenar (stop) el ataque de las babosas para cumplir así con el desafío propuesto por la protagonista del relato. Al ser todos ellos objetos útiles a tal efecto y relacionados con el contexto en el que se desarrolla la acción, su presencia tampoco debería resultar sorpresiva para el lector. En lo que a las amplificaciones respecta, la más evidente volvería a ser la apariencia física del príncipe, ya que no existe referencia alguna a su aspecto en el elemento narrativo. Por último, la autora aplica de nuevo la elisión a la figura de la princesa dando la orden que desencadena la escena: el texto la menciona (She asked...), pero la ilustración no la reproduce.

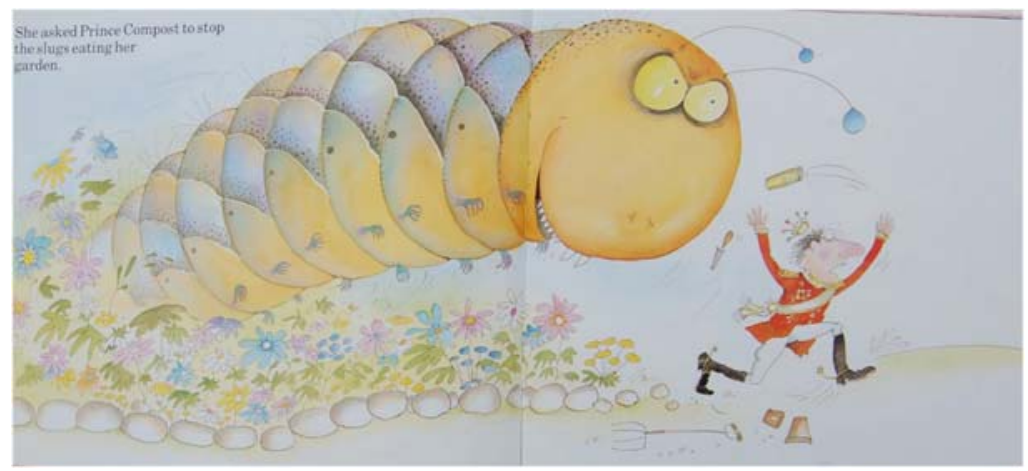

Imagen 2. Princess Smartypants

Fuente: Cole (1988/1997, pp. 7-8)

Cole repite el patrón de los ejemplos 1 y 2 en muchos otros pasajes de la obra, como en la página 9 , donde una acción a priori tan rutinaria e inofensiva como dar de comer a unas mascotas deviene en toda una prueba de valor cuando la ilustración nos muestra que estas no son otra cosa que seres monstruosos y amenazantes. Las dinámicas que se crean en todos estos casos son, como señalaban Nikolajeva y Scott (2000) y como 
demuestra el análisis realizado hasta el momento, de contrapunto, ya que el elemento verbal y el visual se combinan para dar al conjunto un significado inalcanzable individualmente. Sin embargo, pese a que las conclusiones finales puedan ser análogas, el razonamiento que nos lleva hasta ellas es ahora más elaborado y nos permite identificar los distintos pasos que Cole sigue para crear esta interrelación. A partir de la aplicación de procedimientos de traducción que modifican el mensaje del texto original, la ilustradora consigue crear un juego de significados que deriva en una situación humorística. En este sentido, conviene destacar el papel que juega la variación, ya que es la que sustenta el cambio de tono y, en consecuencia, la principal causante de la ironía que logran crear las escenas.

Sin embargo, el hecho de que las relaciones de contrapunto sean la norma, no implica que conformen una constante absoluta. En algunas páginas (contadas, eso sí), la dinámica que se produce entre texto e imagen cambia. Sirva como ejemplo la escena en la que el elemento narrativo expone lo siguiente (véase imagen 3): "It is high time you smartened yourself up," said her Mother, the Queen. "Stop messing about with those animals and find yourself a husband!" Al fijarnos en la ilustración, inmediatamente identificamos disonancias entre lo verbal y lo visual, fundamentadas en los detalles añadidos (y omitidos) por Cole. Sin embargo, también pueden apreciarse ciertos paralelismos entre ambos elementos. 


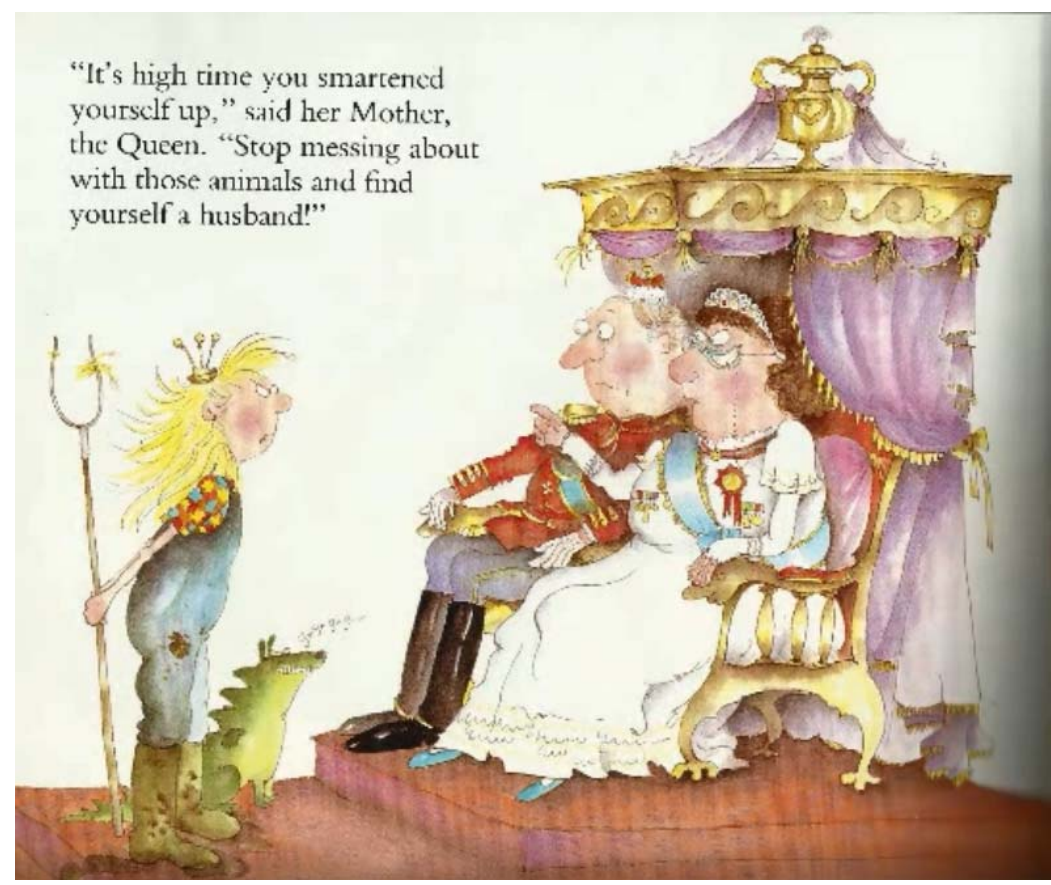

Imagen 3. Princess Smartypants

Fuente: Cole (1988/1997, p.5)

Estas semejanzas obedecen a una traducción literal, que afecta, por ejemplo, a la actitud de la reina, abroncando claramente a su hija, o a la presencia de un pequeño ¿dinosaurio? que encarna la referencia a those animals. También es cierto que, en relación con el discurso de la reina, Cole combina la literalidad con la elisión, obviando cualquier referencia a It is high time you smartened yourself up o a su orden de que encuentre un marido (segmento que, por otro lado, anticipa al lector parte de lo que ocurrirá en páginas posteriores).

El empleo de la explicitación también crea lazos entre el elemento verbal y el visual, ya que aporta información que el lector puede deducir fácilmente leyendo el texto. En este caso, el segmento mess about with those animals aparece representado a través de una princesa vestida con un mono y unas botas sucias, horca en mano. Si bien existen muchas formas de enredar con nuestras mascotas, también es cierto que la gran mayoría implica juegos y actividades que nos llevan a ensuciarnos, por lo que el lector probablemente no se sorprenda ante este retrato de la princesa. Computan también como explicitación las ropas de la reina y el 
rey, ambas en línea con lo que el lector podría esperar de dos miembros de la realeza, aunque la figura del monarca merece mayor análisis en párrafos posteriores.

En lo que respecta a las amplificaciones, Cole también decide añadir información nueva a lo expuesto en el texto. Al margen del aspecto físico de todos los personajes (nunca descrito en palabras), lo más sorprendente es, probablemente, la aparición del rey, al que no se menciona en el elemento narrativo y al que la autora/ilustradora sienta en segundo plano y actitud silente junto a su esposa. Asimismo, el añadido del trono sitúa al lector en un entorno específico: un escenario interior, concretamente dentro de palacio.

En este caso, la dinámica derivada de los procedimientos de traducción aplicados por la ilustradora podría etiquetarse como complementaria en ambos sentidos. Por un lado, el texto es necesario para comprender parte del contenido de la reprimenda que la reina dirige a su hija. Por otro, Cole interrelaciona texto e imagen de tal modo que la segunda también completa de manera significativa al primero, aportando nuevos detalles que, en parte, conectan con el papel preponderante que la autora/ilustradora da a la mujer en su historia. El rey ni siquiera es mencionado en el texto y, pese a aparecer en la imagen, su rol es completamente secundario: eclipsado por la reina, ella es quien lleva la voz cantante y la que representa, al fin y al cabo, la autoridad en la escena. Vemos por tanto cómo elemento verbal y visual no llegan a contraponerse, sino que el uno enriquece al otro (y viceversa), aportando nueva información e interpretaciones al binomio.

Tomando la obra en su conjunto, las distintas dinámicas formadas entre elemento narrativo y no narrativo en Princess Smartypants demuestran la aplicación de una estrategia oblicua en la transmutación del texto a la imagen, ya que prevalecen a lo largo del álbum relaciones de contrapunto entre las que se intercalan ocasionalmente dinámicas de complementariedad. Ambos escenarios llevan a la ilustración a desligarse (en mayor o menor medida) del significado que estrictamente transmitiría el texto, lo que demuestra la intención de Cole de utilizar las imágenes, no como una réplica del mensaje verbal, sino como un vehículo para explotar sus posibilidades y multiplicar sus significados (algo, como se mencionaba en apartados previos, íntimamente ligado a ciertas traducciones).

Pese a que por motivos de extensión no se ha analizado en detalle ningún ejemplo concreto, el modelo de estudio propuesto en este trabajo resulta también aplicable a otros escenarios en los que las dinámicas creadas son más sencillas. En su artículo, Nikolajeva y Scott (2000) señalan 
que estas son comunes a un gran volumen de álbumes ilustrados, y ejemplifican su afirmación a través de obras como Curious George (Rey y Rey, 1941) o la ya citada Sylvester and the Magic Pebble (Steig, 1969). En estos casos, las ilustraciones tienden bien a replicar información o bien a complementarse con el elemento narrativo, añadiendo información extra de la que uno $u$ otro otro carece a través de adiciones menores (Nikolajeva y Scott, 2000, p. 229).

Implementar el modelo de análisis anterior sobre ejemplos como estos permitiría comprobar, en contextos diferentes y de forma rigurosa, cómo las dinámicas creadas por autores e ilustradores pueden de nuevo estudiarse a través de procedimientos de traducción como los citados en la sección metodológica de este artículo. Del mismo modo, posibilitaría explorar puntos similares a los abordados en este trabajo y examinar si se cumplen o no ciertos presupuestos. Dado que las imágenes en estos casos tienden a trazar conexiones más firmes con el texto original, podría testarse de una manera sistemática y consistente si, como las afirmaciones de Nikolajeva y Scott parecen indicar, prevalece en las ilustraciones la traducción literal, combinada puntualmente con explicitaciones y amplificaciones menores, o si la estrategia preponderante es, al contrario que en la obra de Cole (1988/1997), la directa. Futuros estudios en este sentido permitirían comprobar estas hipótesis y arrojar nuevos e interesantes datos sobre la vertiente traductológica de las decisiones del dibujante en álbumes ilustrados de menor complejidad.

El estudio de los resultados del análisis realizado hasta ahora puede, como se anticipaba en apartados previos, conducir a inferencias relacionadas con otros aspectos del proceso de lectura. Uno de ellos es el nivel de exigencia al que cada dinámica, estrategia y conjunto de procedimientos someten al lector. De este modo, dinámicas de contrapunto o contradictorias, formadas por procedimientos como la amplificación, la variación, la explicitación o la elisión, requieren una mayor capacidad cognitiva y esfuerzo, ya que obligan al receptor a deducir el mensaje a partir de informaciones verbales y visuales diferentes (Moya Guijarro y Pinar Sanz, 2007). Por el contrario, un enfoque directo en el que predomine la traducción literal, derivará en dinámicas simétricas o de mínima ampliación, menos exigentes y que, como señalan Moya Guijarro y Pinar Sanz (2007), guían y sirven como apoyo al lector para comprender la historia, enfatizando aspectos clave de la narración.

También, aunque no siempre, la presencia de una $u$ otra dinámica(s), estrategia(s) o procedimiento(s), puede relacionarse con la edad recomendada de la obra en cuestión. La explicación puede obedecer a lo apuntado por Moya Guijarro y Pinar Sanz (2007), quienes señalan que las 
dinámicas que fundamentalmente replican la información textual suelen ser más comunes en etapas iniciales. En estadios posteriores, sin embargo, el empleo de otras dinámicas es más habitual e incluso aconsejable, ya que interrelaciones complejas como las de la obra de Cole suponen un desafío potencialmente estimulante para el lector y requieren de un público capaz de leer entre mensajes contradictorios para ser adecuadamente entendidas.

\section{CONCLUSIONES}

Como se ha venido comprobando a lo largo de este trabajo, las dinámicas texto-imagen son un elemento esencial dentro del álbum infantil ilustrado ya que, ulteriormente, son las que dan forma al mensaje que la obra quiere transmitir. Estas dinámicas se han venido analizando desde un prisma fundamentalmente descriptivo en el que no se profundiza en los pasos intermedios que derivan en la creación de una imagen concreta a partir de un texto dado. Los estudios de estas dinámicas tienden a exponer lo que se ha reproducido, modificado $u$ omitido, centrándose en la información que contiene cada elemento, pero sin explorar de manera exhaustiva los distintos procesos que pueden dar lugar a una determinada interrelación entre texto e ilustración.

Esto último es lo que, tradicionalmente, ha abordado gran parte de los estudios de traducción: las conexiones entre un TO y su TM, así como las decisiones y fenómenos que han dado lugar a ese resultado particular. Por consiguiente y sin menoscabo de otras propuestas diferentes, el análisis de la labor del ilustrador desde un prisma traductológico puede ayudar a etiquetar los procesos ocurridos en el paso de lo lingüístico a lo icónico, explicar mejor por qué se compone una u otra dinámica y, al mismo tiempo, subrayar los nexos de unión existentes entre traducir e ilustrar que este artículo ha puesto de manifiesto. El modelo propuesto cumple con estos propósitos y resulta, además, sumamente abarcador, puesto que permite cubrir la fenomenología relacionada tanto con dinámicas simétricas como con otras más complejas.

Las recogidas en estas páginas son, sin embargo, solo algunas muestras de la conexión entre ambas disciplinas. Como afirma Pereira (2007), existen otras como la adaptación que se produce en el producto dependiendo de la audiencia, la influencia del trabajo original o el peso que la industria editorial tiene a la hora de determinar el resultado. Todos estos elementos abren numerosas posibilidades en las que profundizar en futuros estudios $y$, sin duda, ponen de manifiesto los lazos que unen a ilustradores y traductores pese a lo distinta que nos puede parecer su labor a simple vista. 


\section{REFERENCIAS BIBLIOGRÁFICAS}

Blake, Q. (1995). Míster Magnolia (M. Azaola, trad.). Madrid, España: Altea. (Original publicado en 1980).

Boegehold, L. (1999). Contando ositos de goma (P. Garriga i Anquera, trad.). Barcelona, España: Zendrera Zariquiey. (Original publicado en 1997).

Calabrese, O. (2000). Lo strano dell equivalenza imperfetta (modeste ossrevazioni sulla traduzione intersemiotica). VS, 85-86, 101-120.

Cañamares Torrijos, C. (2007). Modelos de relatos para «primeros lectores». Cuenca, España: Ediciones de la Universidad de CastillaLa Mancha.

Castro, G. (2000). De cómo nacieron las sirenas. Barcelona, España: Edebé.

Cole, B, (1997). Princess Smartypants. Nueva York, Estados Unidos: PaperStar Books. (Original publicado en 1988).

Echauri-Galván, B. (2019). Translation depends on the artist: Two approaches to the illustrations of James and the Giant Peach through the prism of intersemiotic translation. Babel, 65(1), 61-80.

Eco, U. (2008). Decir casi lo mismo (H. Lozano Millares, trad.). Barcelona, España: Lumen. (Original publicado en 2003).

Delisle, J., Lee-Jahnke, H. y Cormier, M.C. (1999). Terminologie de la traduction - Translation terminology. Ámsterdam, Países Bajos: John Benjamins Publishing.

Hurtado Albir, A. (2001). Traducción y traductología, introducción a la traductología. Madrid: Cátedra

Jakobson, R. (2000). On linguistic aspects of translation. En L. Venuti (Ed.). The Translation Studies Reader (pp. 113-118). Nueva York, Estados Unidos: Routledge. (Original publicado en 1959)

Lewis, D. (2001). Reading Contemporary Picturebooks. Nueva York, Estados Unidos: Routledge Falmer.

Malone, J.L. (1988). The science of linguistics in the art of translation. Nueva York, Estados Unidos: State University of New York Press.

Martinovski, V. (2016). Ekphrasis and intersemiotic transposition: Literature, visual arts, and culture, PrimerjalnaKnjizevnost, 39(2), 11-24. 
Moya Guijarro, A.J. y Pinar Sanz, M.J. (2007). La interacción texto/imagen en el cuento ilustrado. Un análisis multimodal, Revista OCNOS, 3 , 21-38.

Nida, E.A. (1964). Toward a science of translating. Leiden, Países Bajos: E. J. Brill.

Nikolajeva, M. y Scott, C. (2000). The dynamics of picturebook communication. Children's Literature in Education, 31(4), 225-239.

Nikolajeva, M. y Scott, C. (2001). How Picturebooks Work. Nueva York, Estados Unidos: Garland Publishing.

Nodelman, P. (1988). Words about Pictures: The Narrative Art of Children's Picturebooks. Atenas, Estados Unidos: The University of Georgia Press.

Pereira, N.M. (2007). Book illustration as intersemiotic translation: The case of Alice in Wonderland in Brazil, en D. Kenny y K. Ryou (Eds.). Across boundaries: International perspectives on Translation Studies (pp.56-77). Newcastle, Reino Unido: Cambridge Scholars Publishing.

Pereira, N. M. (2008). Book illustration as (intersemiotic) translation: Pictures translating words. Meta 53(1), 104-119. doi.org/10.7202/017977ar

Rey, M. y Rey, H.A. (1941). Curious George. Boston, Estados Unidos: Houghton Mifflin Harcourt.

Sánchez Corral, L. (1995). Literatura infantil y lenguaje literario. Barcelona, España: Paidós.

Schwarz, J. (1982). Ways of the illustrator: Visual communication in children's literature. Chicago, IL: American Library Association.

Sipe, L.R. (1998). How picture books work: A semiotically framed theory of text-picture relationships. Children's Literature in Education, 20(2), 97-108.

Steig, W. (1969). Sylvester and the Magic Pebble. Nueva York, Estados Unidos: Windmill Books.

Vázquez Ayora, G. (1977). Introducción a la traductología. Washington, Estados Unidos: Georgetown University Press.

Vinay, J. P. y Darbelnet, J. (1995). Comparative Stylistics of French and English: A Methodology for Translation. Ámsterdam, Países Bajos: John Benjamins. (Original publicado en 1958). 